\title{
Caracterização de um bocal supersônico para uma bancada de testes de combustores supersônicos
}

\section{Characterization of a supersonic nozzle for a supersonic combustion test bench}

Ericles Willian Nunes e Silva ${ }^{1}$, Jefte da Silva Guimarães²* ${ }^{*}$ Valéria Serrano Faillace Oliveira Leite², Demerval Carinhana Junior²

\section{RESUMO}

Equipamentos de ensaio em solo são utilizados como ferramentas para a obtenção de dados representativos de um voo real. Atualmente, o Instituto de Estudos Avançados (IEAv) possui uma versão-piloto de uma bancada de testes de combustores supersônicos (BTCS) que está sendo utilizada para estudos de escoamentos supersônicos e estudos de combustão supersônica, e também para obtenção de dados que ajudarão na montagem da BTCS definitiva. A BTCS-piloto é composta basicamente de uma câmara de combustão acoplada a um bocal supersônico para acelerar o escoamento até as condições de ensaio. Este trabalho tem como objetivo o desenvolvimento de bocais para serem utilizados na BTCS-piloto, visando a obtenção de números de Mach entre 2 e 3, adaptados à vazão e à pressão fornecida atualmente pela linha de alimentação de gases da bancada.

Palavras-chave:Bocal supersônico, Ensaios em solo, Técnica schlieren.

\section{ABSTRACT}

Ground test equipment is used as a tool for obtaining representative data of a real flight. The Instituto de Estudos Avançados (IEAv) currently has a pilot version of a supersonic combustion test bench (SCTB), which is being used for supersonic flow and supersonic combustion studies, and also for obtaining data that will assist in the assembly of the definitive SCTB. The SCTB pilot is basically formed of a combustion chamber coupled to a supersonic nozzle designed to accelerate it to test conditions. This work purpose is to develop nozzles to be used in SCTB pilot, aiming to obtain Mach numbers between 2 and 3, adapted to the flow and pressure currently supplied by the bench gas supply line.

Keywords:Supersonic nozzle, Ground tests facilities, Schlieren technique. 


\section{INTRODUÇÃO}

O Instituto de Estudos Avançados (IEAv) vem desenvolvendo pesquisas na área de veículos hipersônicos por meio do projeto PropHiper (propulsão hipersônica 14-X), tendo em vista que essa área de estudo tornou-se estratégica para os Ministérios da Defesa e da Ciência e Tecnologia, que visam garantir igualdade tecnológica com as demais nações ${ }^{1}$. Este projeto tem como objetivo o desenvolvimento de um veículo que seja capaz de demonstrar os conceitos de propulsão hipersônica por meio do desmontador 14-X.

O regime de trabalho hipersônico pode ser definido quando Mach > 5, onde Mach $(M)$ é dado pela razão entre a velocidade do escoamento $(V)$ e a velocidade do som $(a)$. Já o regime supersônico pode ser definido quando $M>1^{2,3}$.

A Fig. 1 mostra o modelo do $14-\mathrm{X}^{4}$ que vem sendo utilizado em ensaios laboratoriais em túneis de choque disponíveis na Divisão de Aerotermodinâmica e Hipersônica (EAH) do IEAv. O modelo em desenvolvimento usará a tecnologia waverider, no qual o veículo hipersônico usa a própria onda de choque formada no seu bordo de ataque para gerar sustentação do veículo, e a tecnologia scramjet (supersonic combustion ramjet), que utiliza a compressão do ar provocada pela onda de choque para comprimir o escoamento no interior do seu combustor e, assim, gerar propulsão e manter o veículo em voo.

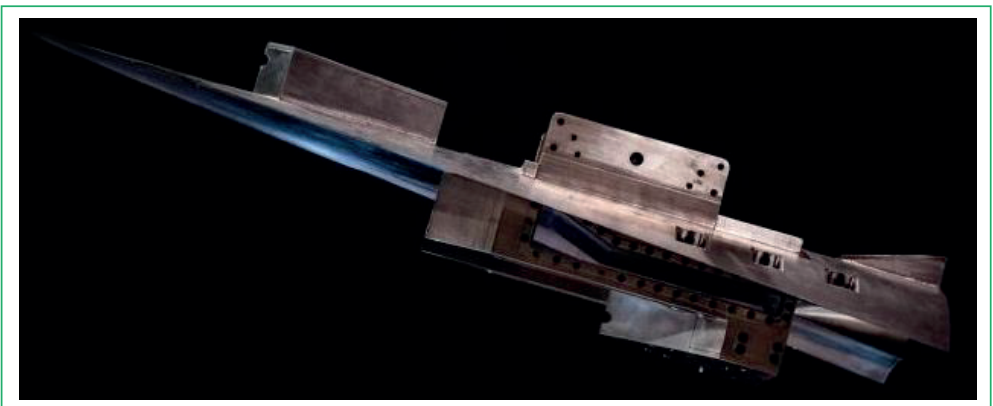

Figura 1: Modelo do 14-X testado em túnel de choque.

Um conjunto de três equipamentos de ensaio em solo é utilizado para o estudo do escoamento hipersônico e da combustão supersônica: um túnel de choque, um lançador hipersônico de massa e a bancada de testes de combustores supersônicos (BTCS). Esses três equipamentos representam o conjunto necessário para a realização de ensaios de aerotermodinâmica e hipersônica ${ }^{5}$.

\section{Bancada de testes de combustores supersônicos (BTCS)}

O estudo experimental da combustão supersônica tem sido de interesse de diversos países desde os anos $1950^{6}$, o que torna a BTCS um equipamento de interesse dos grandes centros de pesquisas aeroespaciais (Fig. 2).

A BTCS pode ser encontrada em duas configurações principais: uma por aquecimento com arco elétrico, em que uma fonte de alta tensão conectada às extremidades do gerador de ar viciado (GAV) gera um arco elétrico que aquece o ar, que por sua vez, é acelerado por um bocal até as condições de ensaio desejadas; e outra com aquecimento do ar por combustão no interior do GAV, na qual o ar

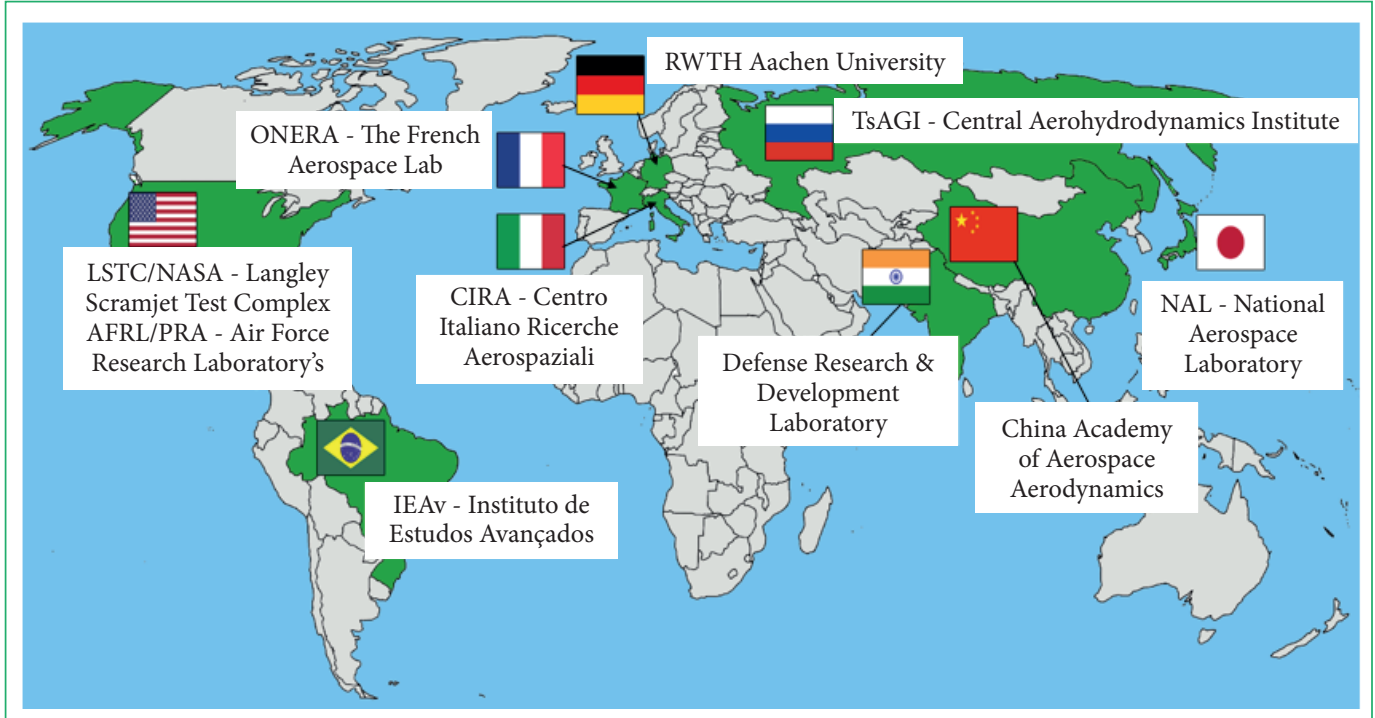

Figura 2: Cenário mundial da utilização de BTCS?7. 
é aquecido através da combustão e acelerado por um bocal convergente-divergente. O GAV recebe esse nome devido à utilização de resíduos da combustão do combustível para o aquecimento do $\operatorname{ar}^{7,8}$.

A BTCS é constituída basicamente pelo GAV, por uma placa de injeção de combustíveis acoplada às suas extremidades, utilizada para pré-mistura e injeção dos gases e por um bocal supersônico (convergente-divergente) cuja finalidade é acelerar o escoamento aquecido até as condições de ensaio9. Sua finalidade é de simular as condições do escoamento gerado pelas ondas de choque provocadas pela geometria do veículo hipersônico na entrada do combustor de um scramjet.

Para a montagem da BTCS que será utilizada para ensaiar o combustor do 14-X, faz-se necessária a construção de um laboratório adequado juntamente com uma sala de controle, para a segurança dos operadores, bem como um sistema de alimentação de reagentes adequado, incluindo as linhas de ar comprimido, de gás natural veicular (GNV) e de oxigênio. Tendo em vista que o projeto do IEAv ainda está em fase de desenvolvimento, foi fabricada uma unidade-piloto da BTCS em aço, com comprimento de 700 mm e diâmetro interno de $150 \mathrm{~mm}$ (Fig. 3). Entretanto utilizaram-se o mesmo bocal e a mesma placa de injeção de combustível projetados para a BTCS que será utilizada para ensaiar o combustor do $14-\mathrm{X}^{7}$.

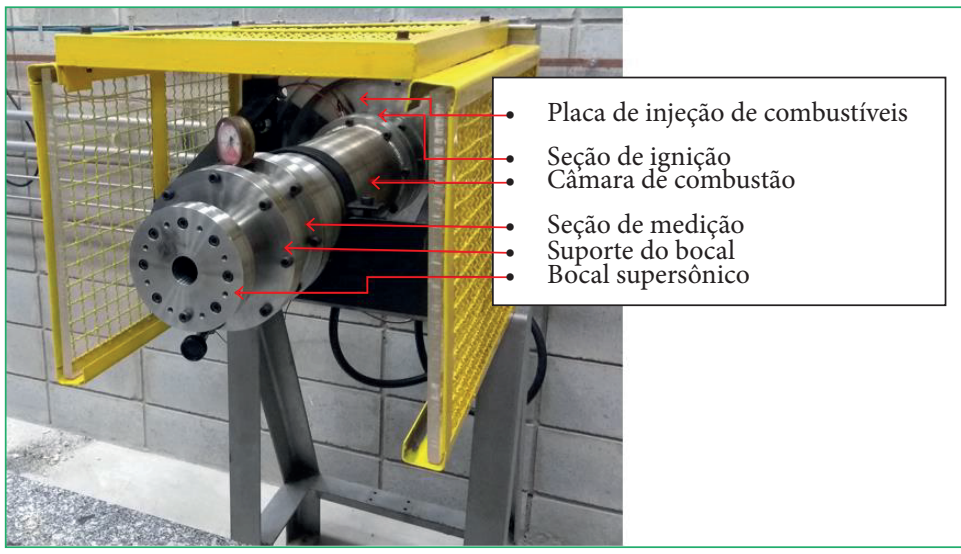

Figura 3: Bancada-piloto para testes de combustores supersônicos montada no IEAv.

Após a realização de alguns ensaios experimentais, observou-se uma limitação da BTCS-piloto em atingir uma pressão de estagnação necessária na entrada do bocal para que fosse possível a obtenção de um escoamento completamente desenvolvido. Isso se deve ao fato de que o bocal utilizado possuía um diâmetro de garganta muito grande para o atual sistema de alimentação de gases. Dessa forma, o presente trabalho tem o objetivo de desenvolver um bocal adequado de Mach 2 a 3 para a BTCS-piloto, com um diâmetro de garganta máximo que permita atingir a pressão de estagnação necessária para a geração de um escoamento completamente desenvolvido, e também estudar outros possíveis bocais que poderão ser aplicados nesta configuração de BTCS.

\section{MÉTODOS}

Realizados os ensaios com o bocal oriundo da BTCS definitiva, observou-se que a pressão máxima de estagnação medida foi de $p_{0}=500 \mathrm{kPa}$ ( 5 bar), sendo que a pressão de estagnação necessária para a bancada produzir um escoamento completamente desenvolvido para um número de Mach em torno de 2,6 deveria ser em torno de $p_{0}=2000 \mathrm{kPa}$ (20 bar), uma vez que a bancada está aberta para a atmosfera (+/- $100 \mathrm{kPa}$ ou 1 bar) e a relação de pressões $p_{\delta} / p$ para esse número de Mach é igual a 19,95. Observou-se também que o fato de a pressão de estagnação máxima alcançada ser $500 \mathrm{kPa}$ era devido ao diâmetro da garganta do bocal (Ø20 mm) ser grande demais para a vazão de alimentação de gases existente na BTCS-piloto. Nesse caso, para manter o sistema de alimentação de gases utilizado pela BTCS-piloto, foi necessário projetar um novo bocal com um diâmetro de garganta que fornecesse a pressão de estagnação necessária para as condições desejadas nos experimentos (Mach 2 a 3).

\section{Teste de estanqueidade}

Inicialmente, foi realizado um teste de estanqueidade para averiguar a existência de possíveis vazamentos no sistema da BTCS-piloto. Para a realização do teste, tanto o bocal como o suporte do bocal foram retirados do conjunto; sendo montado um flange de alumínio no lugar do bocal, de forma que todo o sistema permanecesse pressurizado. Por questões de segurança, uma vez que todo o sistema foi pressurizado, instalou-se uma válvula de alívio no centro de medições, de forma que fosse possível o alívio de pressão de maneira segura, após a realização dos ensaios. A Fig. 4 mostra a montagem da BTCS preparada para o teste de estanqueidade, onde é possível ver o flange de alumínio conectado na saída da BTCS e a válvula de alívio de pressão instalada no centro de medições. 


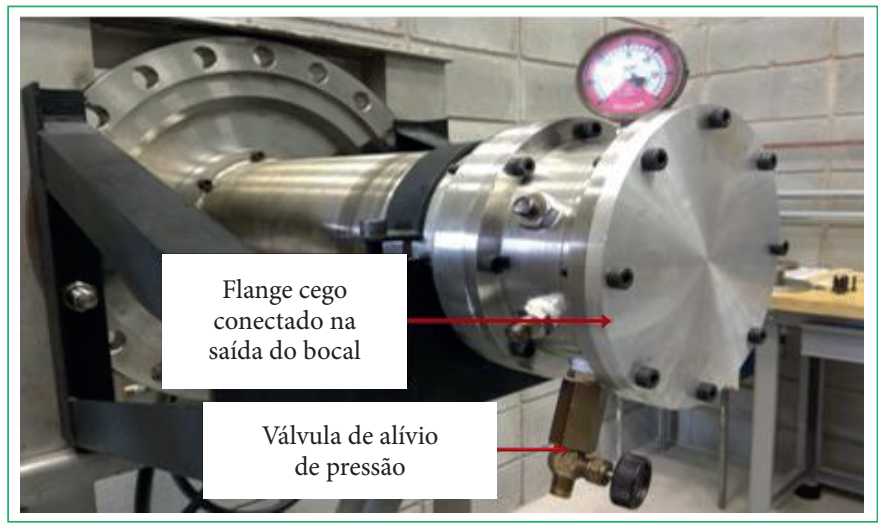

Figura 4: Montagem da BTCS-piloto para a realização do teste de estanqueidade.

Durante a realização do teste de estanqueidade, foram detectados pontos de vazamento de gás nas áreas de fixação do conjunto, como entre a placa de injeção e a câmara de combustão, a câmara de combustão e o centro de medição, e o centro de medição e o flange. Como forma de solucionar os vazamentos de gás encontrados, optou-se pela vedação do sistema por meio da utilização de papelão hidráulico (junta mecânica) S1212 da fabricante Teadit, que tem como característica trabalhos com pressão de até $14000 \mathrm{kPa}$ (140 bar) e temperaturas de até $540{ }^{\circ} \mathrm{C}^{10}$.

Com a confecção das vedações, o conjunto foi novamente montado para a realização de um novo teste de estanqueidade, sendo verificado se as vedações selecionadas se adequavam ao sistema da BTCS. Após nova pressurização e estabilização do sistema, foi possível identificar a ausência de vazamento no conjunto, sendo que tanto o manômetro da entrada da câmara de combustão quanto o manômetro do centro de medições permaneceram com a mesma pressão liberada pelo cilindro por $1 \mathrm{~h}$, tempo superior aos tempos de ensaios experimentais na BTCS, que são de aproximadamente $60 \mathrm{~s}$. Na Fig. 5 é possível visualizar o momento em que o sistema se encontrava completamente estabilizado, quando foram registradas a pressão de entrada da câmara de combustão e a pressão no centro de medições, registradas a $1500 \mathrm{kPa}$ (15 bar).

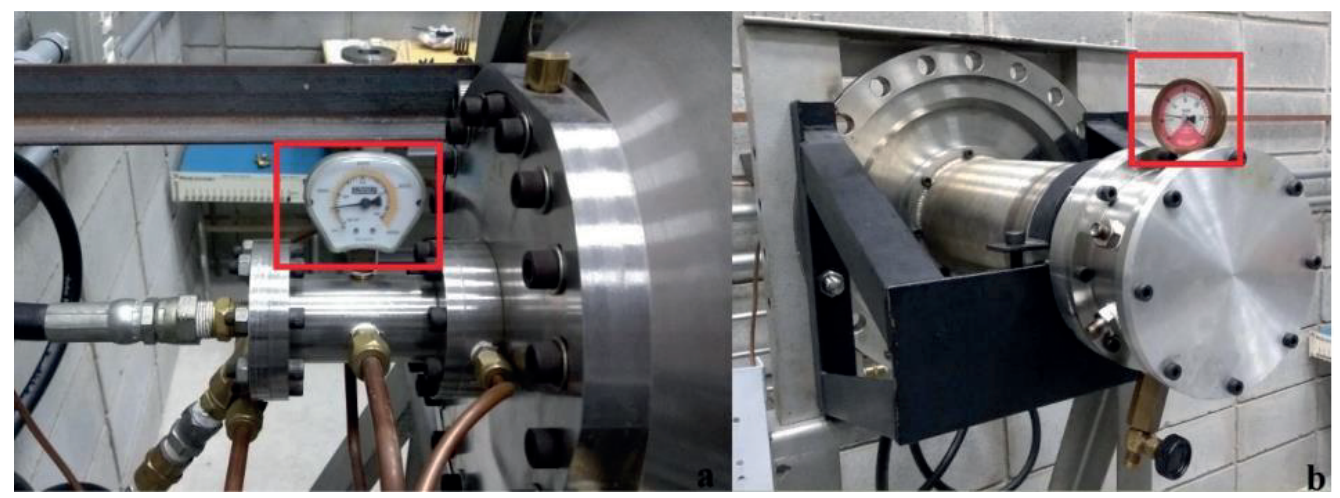

Figura 5: Registro da pressão na entrada da câmara de combustão (a) e no centro de medições (b) durante o teste de estanqueidade.

Após todos os vazamentos de gases existentes no conjunto da BTCS-piloto serem sanados, deu-se início ao desenvolvimento de um bocal que fornecesse as condições necessárias para um escoamento completamente desenvolvido para o sistema de gases da BTCS.

\section{Método semiempírico para determinação do bocal}

Tendo em vista que não era possível medir com exatidão a vazão do escoamento nas linhas de alimentação de gases da bancada, o método elaborado consistiu em encontrar o maior diâmetro de garganta possível para pressão de estagnação de $2000 \mathrm{kPa}$ (20 bar) de forma experimental. Para isso, foi necessária a confecção de um flange com um furo central que serviu de suporte para um simulador de bocal, onde foram realizados furos escalonados de $0,5 \mathrm{~mm}$, partindo de $1,0 \mathrm{~mm}$ e medindo-se a pressão de estagnação para cada furo realizado. Quando a pressão de estagnação medida atingisse um mínimo em torno de $2.000 \mathrm{kPa}$ (20 bar), o furo correspondente a essa pressão seria o diâmetro máximo possível que a garganta do bocal deveria possuir.

A Fig. 6(a) apresenta o flange adaptador confeccionado em aço inox utilizado para fixação do simulador do bocal e a Fig. 6(b) apresenta o simulador do bocal confeccionado em alumínio, onde foram realizados os furos escalonados. 


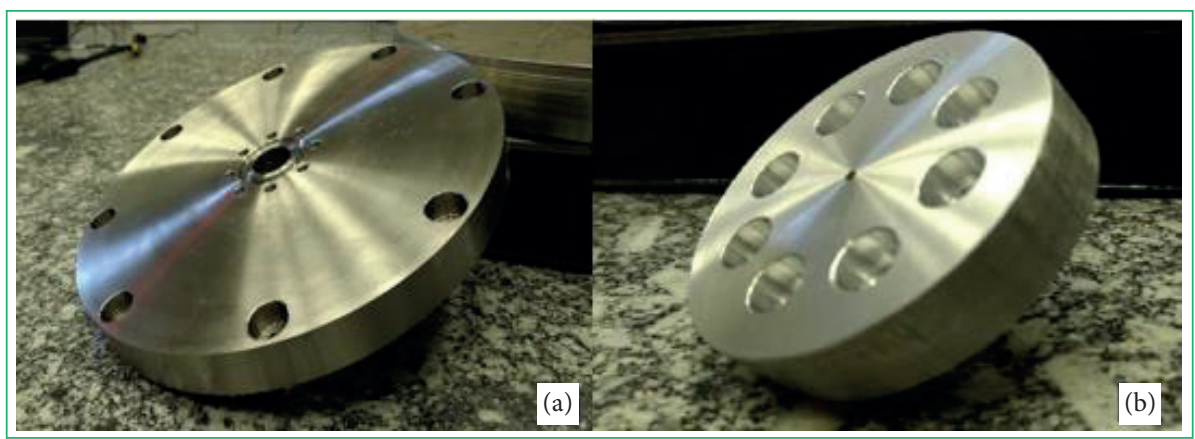

Figura 6: Flange adaptador do simulador do bocal (a) e simulador do bocal (b).

A Fig. 7 apresenta a montagem da BTCS-piloto utilizada para a determinação experimental do novo bocal. Ao atingir a furação de 7,0 mm de diâmetro no simulador do bocal, observou-se que o parâmetro desejado de pressão de estagnação de $2000 \mathrm{kPa}$ (20 bar) foi alcançado utilizando a capacidade máxima do sistema de alimentação da BTCS-piloto. Com isso, determinou-se que o diâmetro da garganta do novo bocal deveria ser de $7 \mathrm{~mm}$, dando-se início ao projeto e à fabricação do novo bocal para o flange adaptativo.

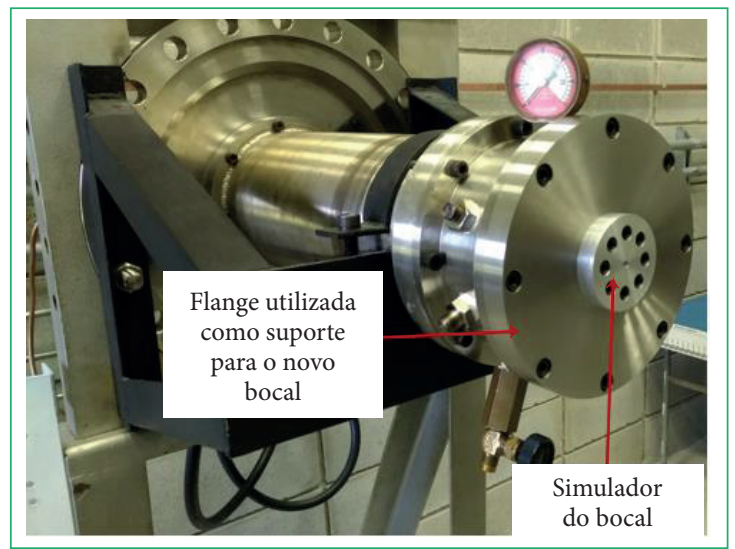

Figura 7: Configuração da BTCS-piloto utilizada para a determinação do novo bocal.

\section{Projeto e confecção do novo bocal}

Tendo sido estipulado o diâmetro máximo da garganta do novo bocal para as condições desejadas, foi utilizada a equação de relações de área (Eq. 1 $)^{11}$ que leva em consideração as razões de área, sendo elas a área da garganta do bocal $\left(A^{*}\right)$ e a área da saída do bocal $(A)$.

$$
\tan \theta=2 \cot \beta\left[\frac{M_{1}^{2} \sin ^{2} \beta-1}{M_{1}^{2}(\gamma+\cos 2 \beta)+2}\right]
$$

Tendo que o número de Mach $(M)$ é uma condição desejada, que a razão entre os calores específicos ( ${ }^{\prime}$ ) é igual a 1,4, e que o escoamento pode ser considerado caloricamente perfeito para um bocal com garganta de $7 \mathrm{~mm}$ de diâmetro e razão de áreas de 2,896, tem-se que o diâmetro da saída do bocal deve ser igual a 11,9 mm. Definindo-se o diâmetro de saída e a garganta, um bocal em alumínio (Fig. 8) foi

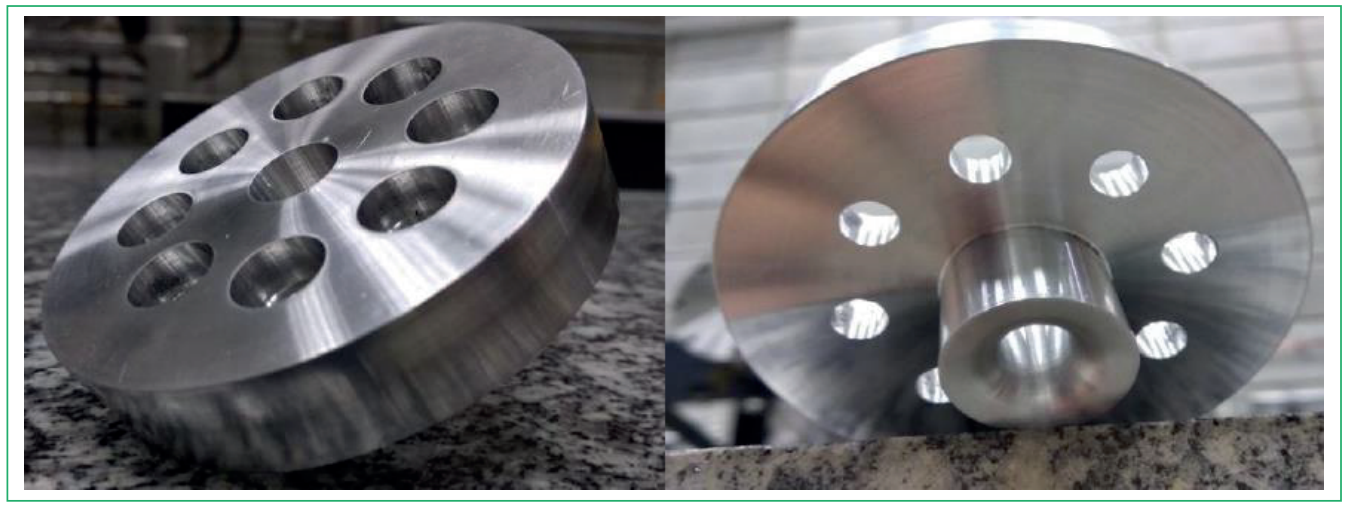

Figura 8: Novo bocal confeccionado em alumínio para ensaio de caracterização do escoamento na saída da BTCS-piloto. 
confeccionado e instalado no flange adaptador no lugar do simulador do bocal. Com a nova montagem, deu-se início à caracterização do escoamento na saída da BTCS-piloto para identificar sua velocidade de saída.

\section{Caracterização do escoamento}

Para a caracterização do escoamento, foi utilizada a técnica schlieren, que se trata de uma técnica óptica não intrusiva que permite a visualização de escoamentos complexos ${ }^{12}$ ao se fazer uso de uma câmera junto com um arranjo específico de equipamentos ópticos, e que pode registrar imagens com diferentes contrastes dependendo da quantidade de luz que a câmera recebe e da visualização da variação da densidade do ar. Uma configuração mais simplificada da técnica schlieren é apresentada na Fig. 9, onde a fonte de luz, os conjuntos de espelhos/lentes, o filtro espacial (faca), e a câmera utilizada para captar os dados podem ser vistos.

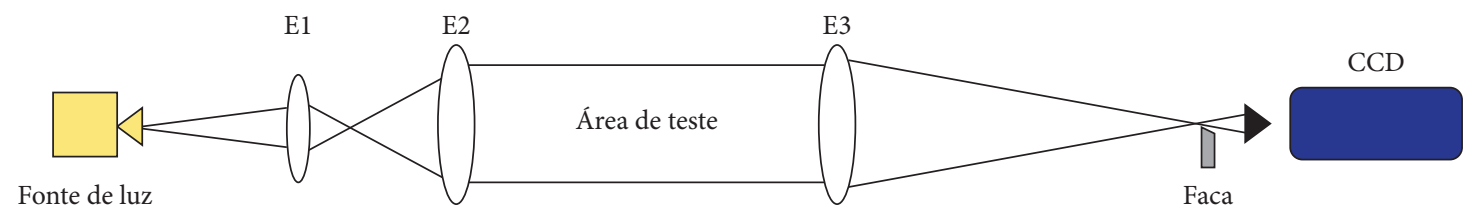

Figura 9: Exemplo de um arranjo schlieren convencional.

Para a montagem da técnica schlieren junto ao experimento, foram utilizados: um conjunto de três espelhos (dois com diâmetro de $35 \mathrm{~cm}$ e um com diâmetro de $10 \mathrm{~cm}$ ), uma fonte de luz LED, um filtro espacial denominado "faca" cuja finalidade é obstruir os raios de luz desviados, uma câmera de alta velocidade e um computador para o armazenamento dos dados. A distância focal utilizada foi de aproximadamente $180 \mathrm{~cm}$. A obtenção das imagens schlieren ocorreu através do arranjo óptico em conjunto com uma câmera de alta velocidade (marca PCO modelo dimax HS).

Por meio da técnica schlieren, foi possível medir o ângulo da onda de choque formada sobre um modelo; no caso, uma rampa (cunha) com um ângulo conhecido. Após se identificar o ângulo da onda de choque ( $\beta$ ) formado sobre a rampa, sabendo-se o ângulo da rampa $(\theta)$, foi possível calcular o número de Mach na saída do bocal da BTCS por meio da equação $\theta-\beta-M$ (Eq. 2).

$$
\left(\frac{A}{A^{*}}\right)^{2}=\frac{1}{M^{2}}\left[\frac{2}{\gamma+1}\left(1+\frac{\gamma-1}{2}\right) M^{2}\right]^{\frac{(\gamma+1)}{(\gamma-1)}}
$$

A Fig. 10 mostra um exemplo da análise do escoamento na saída do bocal por meio da técnica schlieren, onde é possível identificar a direção do escoamento e a onda de choque sendo formada sobre a rampa de teste.

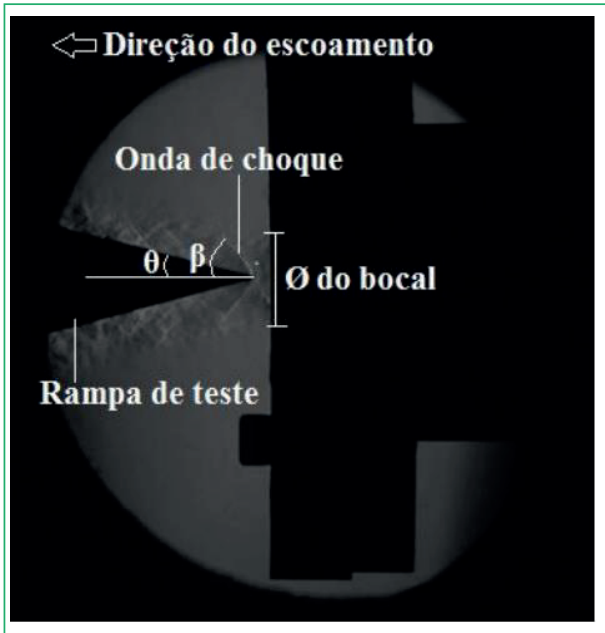

Figura 10: Exemplo da análise do número de Mach por meio da técnica schlieren7.

Os dados obtidos experimentalmente foram comparados com um programa computacional desenvolvido na plataforma de programação Matlab. O programa denominado Bocal_GAV tem como finalidade calcular as condições de escoamento tanto no interior como na saída de um bocal convergente-divergente, sendo dados como inputs uma pressão e uma temperatura de estagnação predefinidas 5 . 
Dependendo das condições de estagnação do problema a ser estudado no Bocal_GAV, o escoamento pode ser tratado como: caloricamente perfeito, termicamente perfeito, em equilíbrio, congelado ou em não equilíbrio. Para o caso apresentado, o módulo caloricamente perfeito foi utilizado na análise dos resultados.

\section{RESULTADOS E DISCUSSÃO}

Com a montagem do novo bocal na BTCS-piloto e a aplicação da técnica schlieren, foi possível observar um escoamento completamente desenvolvido na saída do bocal, o que demonstra a eficiência do bocal projetado. Entretanto, mesmo com o escoamento completamente desenvolvido, não foi possível determinar o número de Mach com a rampa de teste utilizada, tendo que o diâmetro da saída do novo bocal é de apenas $11,9 \mathrm{~mm}$, valor muito inferior à espessura da rampa utilizada, já que o diâmetro da saída do bocal anterior era de 34,04 $\mathrm{mm}$. Essa diferença gerou uma perturbação na ponta da rampa de teste impedindo a identificação do final da onda de choque. Isso pode ser observado na Fig. 11, que apresenta uma sequência de imagens schlieren obtidas com o novo bocal e com a rampa de teste de $\theta=15^{\circ}$ que já vinha sendo empregado nos ensaios anteriores.

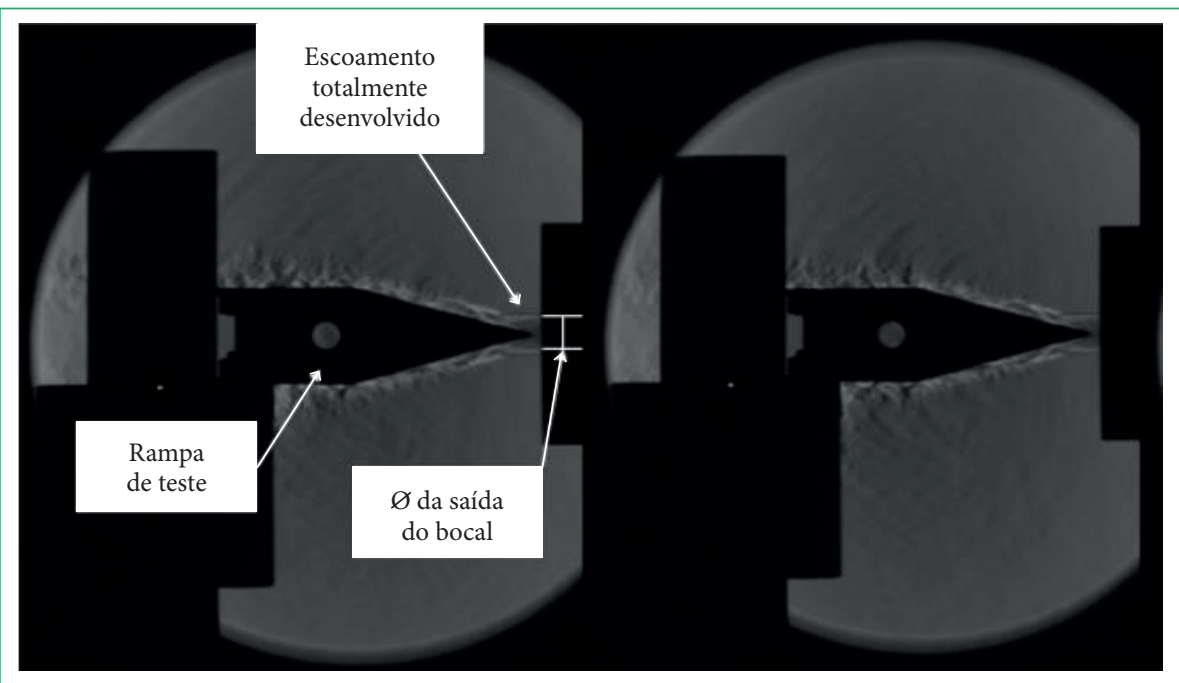

Figura 11: Imagens obtidas através da técnica schlieren (rampa de $\theta=15^{\circ}$ ).

Dessa forma, foi necessário produzir uma rampa de testes com uma espessura menor, que se adequasse ao novo bocal. Assim, foi fabricada uma nova rampa (denominada de rampa mista) com espessura de 10,00 $\mathrm{mm}$, tendo dois ângulos diferentes na parte superior e inferior (ângulo superior $\theta \mathrm{s}=10^{\circ}$ e ângulo inferior $\theta \mathrm{i}=5^{\circ}$ ).

Os ensaios se repetiram utilizando-se a rampa mista, sendo possível a visualização e a medição da onda de choque formada sobre o modelo. Os ensaios com a rampa mista são apresentados na Fig.12, onde se pode ver uma sequência de três imagens schlieren obtidas em um intervalo entre si de $1 \mathrm{~s}$, sendo possível identificar um escoamento completamente desenvolvido e a formação da onda de choque sobre a rampa mista.

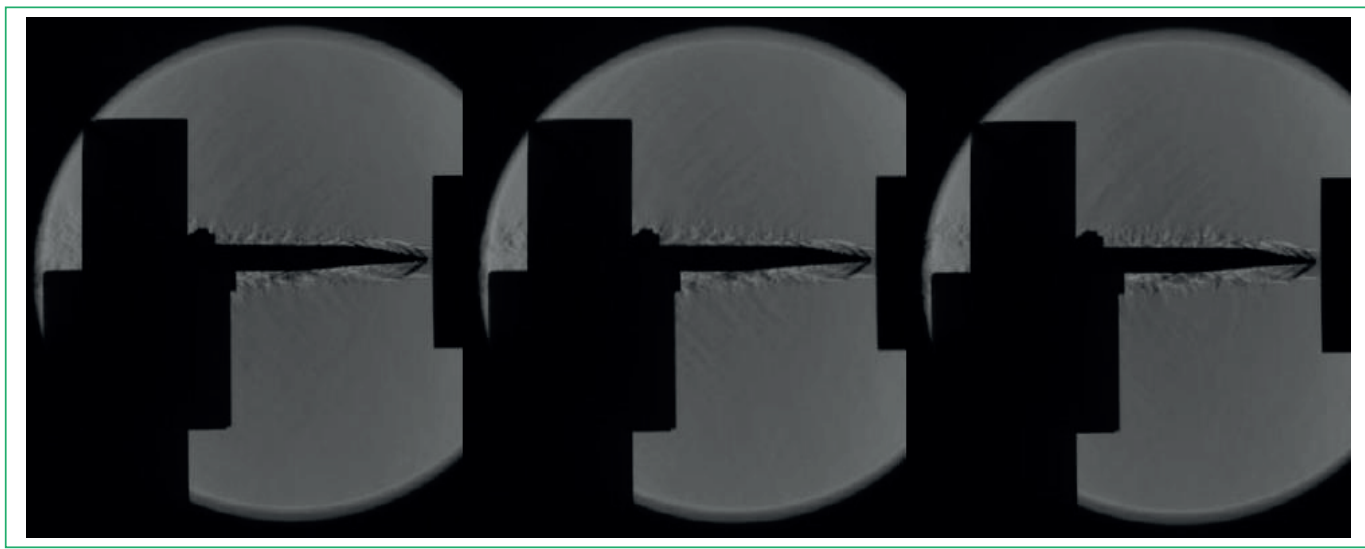

Figura 12: Imagens obtidas através da técnica schlieren (rampa mista). 
Com a confecção da nova rampa de testes (rampa mista) foi possível identificar e validar o número de Mach na saída do bocal aplicando-se a Eq. 2. Essa metodologia se mostrou importante, uma vez que dois ângulos de choque foram analisados para um único experimento.

Os resultados das análises do número de Mach encontrados na saída do bocal para o escoamento incidindo sobre a rampa mista são apresentados nas Tabelas 1 e 2. O número de Mach considerado foi a média de dez experimentos realizados, sendo analisados os ângulos da onda de choque $(\beta)$ para cada um dos lados da rampa de teste mista: ângulo $\theta=5^{\circ}$ (Tabela 1 ) e $\theta=10^{\circ}$ (Tabela 2 ), obtidos através do conjunto de imagens obtidas pela técnica schlieren. Para os dois casos, foi verificado que, mesmo sendo fabricado um bocal para número de Mach igual a 2,6, esse valor de velocidade é encontrado nas bordas do bocal (diâmetro maior $=11,9 \mathrm{~mm}$ ), sendo que o valor do número de Mach encontrado foi igual a 1,9/1,8 no centro do bocal, onde a rampa estava posicionada.

Tabela 1: Número de Mach encontrado através do ângulo $\theta=5^{\circ}$.

\begin{tabular}{|c|c|c|}
\hline Imagem & Ângulo $\beta$ (radianos) & Número de Mach \\
\hline 1 & 0,68573 & 1,76549 \\
\hline 2 & 0,69474 & 1,74531 \\
\hline 3 & 0,61630 & 1,94597 \\
\hline 4 & 0,66964 & 1,80333 \\
\hline 5 & 0,69045 & 1,75484 \\
\hline 7 & 0,7474 & 1,79102 \\
\hline 9 & 0,69474 & 1,74531 \\
\hline 10 & 0,63108 & 1,90345 \\
\hline
\end{tabular}

Tabela 2: Número de Mach encontrado através do ângulo $\theta=10^{\circ}$.

\begin{tabular}{|c|c|c|}
\hline Imagem & Ângulo $\beta$ (radianos) & Número de Mach \\
\hline 1 & 0,68892 & 1,99217 \\
\hline 2 & 0,78540 & 1,76742 \\
\hline 3 & 0,78540 & 1,76742 \\
\hline 4 & 0,68232 & 2,01099 \\
\hline 5 & 0,78540 & 1,76742 \\
\hline 7 & 0,75093 & 1,83809 \\
\hline 9 & 0,78540 & 1,76742 \\
\hline 10 & 0,74838 & 1,84371 \\
\hline
\end{tabular}

A partir dos dados obtidos, o programa Bocal_GAV foi utilizado para o cálculo das condições de temperatura e número de Mach na saída do bocal, sendo aplicadas as mesmas condições dos ensaios experimentais, isto é, pressão de estagnação $=2000 \mathrm{kPa}(20 \mathrm{bar})$, $T_{0}=298,15$ e $\gamma=1$,4. Foram realizadas 5.000 interações para esse cálculo, de forma a garantir que houvesse a convergência dos dados, e os valores se mantiveram estáveis até a quinta casa decimal. Na Fig.13 é apresentada a malha do resultado gerado pelo programa Bocal_GAV para determinação do número de Mach na saída do bocal. A malha apresentada representa metade do bocal, uma vez que ele é simétrico. Os dados analisados foram aqueles obtidos na linha de centro da malha do bocal, uma vez que os dados nos ensaios experimentais também são obtidos no centro do bocal.

Foi possível identificar que o escoamento atingiu $M=1$ na garganta do bocal (eixo x: $7.415 \mathrm{~m}$ ), condição para que o escoamento seja acelerado pela região divergente do bocal. Observando o mapa de cores apresentado na lateral direita da imagem, verificou-se que o número de Mach na parede do bocal corresponde a $M=2,6$; isso é esperado, uma vez que o bocal utilizado possui uma razão de áreas $\left(A / A^{\star}\right)$ para esse valor de Mach. Já o número de Mach encontrado no centro do bocal foi de $M=1,914$ (eixo x: $35 \mathrm{~m}$ ), valor que está 
próximo aos valores encontrados experimentalmente. Na Fig. 13 o eixo $x$ representa o comprimento do bocal desenvolvido, e o eixo $y$ representa metade da altura do bocal, uma vez que ele é simétrico.

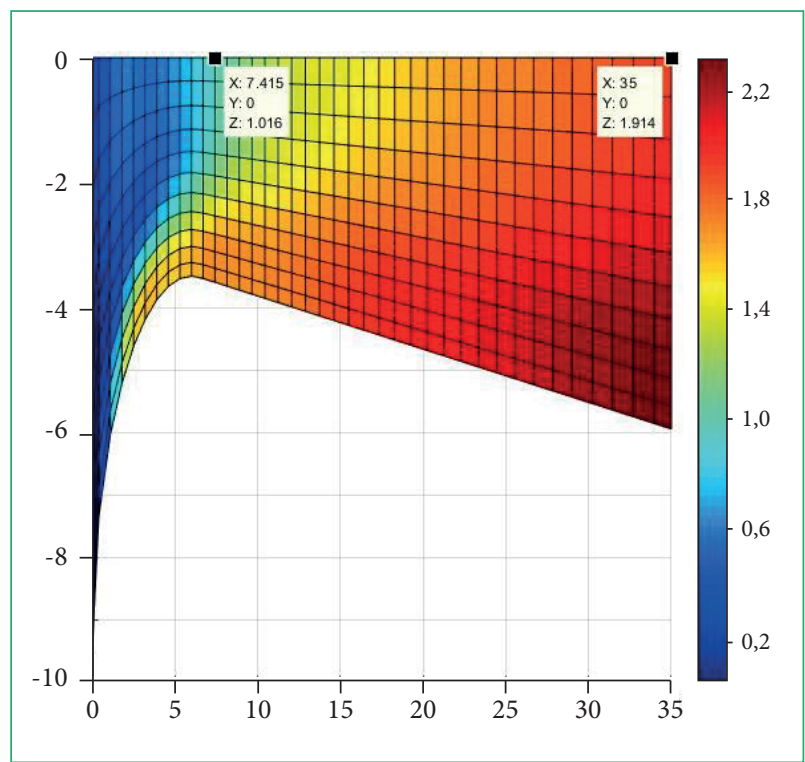

Figura 13: Número de Mach ao longo do bocal para uma pressão de estagnação de 2.000 kPa (20 bar), tendo como saída um número de Mach de 1,91.

\section{CONCLUSÃO}

O objetivo deste trabalho foi fazer com que a BTCS-piloto do IEAv fosse capaz de produzir um escoamento totalmente desenvolvido, com as condições de número de Mach conhecida, para dar início a novos tipos de ensaios e a novas pesquisas que contribuirão para o desenvolvimento do projeto PropHiper, e também para aprimorar a própria BTCS, com o intuito de melhorar os ensaios que possam nela ser realizados futuramente.

O método utilizado para a obtenção do diâmetro de garganta mantendo a pressão de estagnação de $2000 \mathrm{kPa}(20$ bar) mostrou-se válido e eficiente, podendo ser aplicado novamente caso um novo sistema de alimentação seja implementado. Entretanto, como o diâmetro da garganta encontrado para o novo bocal foi de apenas $7 \mathrm{~mm}$, o diâmetro da seção de saída do bocal obteve tamanho de 11,9 mm. Assim, a seção de testes ficou muito reduzida para as escalas de combustores que estavam sendo testados na BTCS.

Através dos números de Mach encontrados para os dois ângulos da rampa mista, foi possível identificar que a metodologia utilizada para a obtenção do valor do número de Mach do escoamento na saída do bocal apresentou um ótimo resultado, podendo ainda ser aprimorado no futuro, tendo que a diferença entre os valores obtidos experimental e computacionalmente foi inferior a $6 \%$.

Como continuação dos trabalhos de melhoria da BTCS-piloto, serão consideradas algumas alternativas para o aumento dos diâmetros das tubulações de alimentação de gases da bancada para, ao aumentar a vazão, ser possível aumentar sua pressão de estagnação e possibilitar a utilização de um bocal com diâmetro de garganta maior e, consequentemente, uma seção de teste maior.

\section{AGRADECIMENTOS}

Os autores agradecem ao Instituto de Estudos Avançados (IEAv) pelo apoio financeiro mediante as bolsas de estudos concedidas. À Divisão de Aerotermodinâmica e Hipersônica (EAH) e a Divisão de Suporte Tecnológico (Sutec) pelo apoio na confecção e ajustagem da BTCS-piloto.

\section{FINANCIAMENTO}

Coordenação de Aperfeiçoamento de Pessoal de Nível Superior [https://doi.org/10.13039/501100002322] 


\section{REFERÊNCIAS}

1. Ministério da Defesa. Portaria Normativa $n^{\circ}$ 1.317/MD, de 4 de novembro de 2004. Aprova a Política de Ciência, Tecnologia e Inovação (C T \& I) para a Defesa Nacional. Ministério da Defesa; 2004. [citado em 5 Ago 2019]. Disponível em: https://www.defesa.gov.br/arquivos/File/ doutrinamilitar/Portarias/1317_2004.pdf

2. Anderson Junior JD. Modern compressible flow: with historical perspective. New York: McGraw-Hill; 2002.

3. Çengel YA, Boles MA. Thermodynamics: an engineering approach. New York: McGraw-Hill; 2006.

4. Inovação Tecnológica. 14-X: Avião hipersônico brasileiro avança rumo ao primeiro voo [Internet]. 2019. [citado em 30 Jul 2019]. Disponível em: https://www.inovacaotecnologica.com.br/noticias/noticia.php?artigo=14-x-aviao-hipersonico-brasileiro\&id=010170190124\#Imprimir

5. Leite VSFO. Caracterização do escoamento de uma bancada de testes de combustores supersônicos alimentada por ar viciado [Tese]. [São José dos Campos]: Instituto Tecnológico de Aeronáutica; 2006.

6. Curran ET. Scramjet engines: the first forty years. J Propul Power. 2001;17(6):1138-48. https://doi.org/10.2514/2.5875

7. Guimarães JS, Brandão KMB, Marcos TVC, Leite VSFO, Carinhana Junior D. Diagnóstico do escoamento a frio de uma bancada de teste de combustores supersônicos. In: X Congresso Nacional de Engenharia Mecânica. Salvador: CONEM; 2018.

8. Brandão KMB. Montagem e caracterização de uma bancada para testes de combustores supersônicos [Dissertação]. [São José dos Campos]: Instituto Tecnológico de Aeronáutica; 2017.

9. Guimarães JS. Investigação do escoamento a frio em uma bancada de testes de combustores supersônicos [Dissertação]. [São José dos Campos]: Instituto Tecnológico de Aeronáutica; 2018.

10. VEIGA JC. Juntas industriais. Rio de Janeiro: Teadit; 2003.

11. Anderson Junior JD. Fundamentals of aerodynamics. Nova York: McGraw-Hill; 2001

12. Settles GS. Schlieren and shadowgraph techniques: visualizing phenomena in transparent media. Berlin: Springer; 2006. https://doi. org/10.1007/978-3-642-56640-0 